OPEN ACCESS

Edited by:

Rajesh Jha

University of Hawaii at Manoa,

United States

Reviewed by:

Utsav Prakash Tiwari,

University of Illinois at

Urbana-Champaign, United States

Xiao Xu,

Wuhan Polytechnic University, China

*Correspondence:

Huihua Zhang

hhzhang2@163.com

†These authors have contributed equally to this work

Specialty section:

This article was submitted to Animal Nutrition and Metabolism,

a section of the journal

Frontiers in Veterinary Science

Received: 29 July 2020 Accepted: 13 October 2020

Published: 11 November 2020

Citation:

Qi Q, Peng Q, Tang M, Chen D and Zhang $H$ (2020) Microbiome Analysis Investigating the Impacts of

Fermented Spent Mushroom

Substrates on the Composition of Microbiota in Weaned Piglets Hindgut. Front. Vet. Sci. 7:584243.

doi: 10.3389/fvets.2020.584243

\section{Microbiome Analysis Investigating the Impacts of Fermented Spent Mushroom Substrates on the Composition of Microbiota in Weaned Piglets Hindgut}

\author{
Qien Qi ${ }^{1,2+}$, Qiaoli Peng ${ }^{1 \dagger}$, Min Tang ${ }^{3}$, Dongling Chen $^{3}$ and Huihua Zhang ${ }^{1 *}$ \\ 'School of Life Science and Engineering, Foshan University, Foshan, China, ${ }^{2}$ Guangdong Province Key Laboratory of Animal \\ Nutritional Control, College of Animal Science, South China Agricultural University, Guangzhou, China, ${ }^{3}$ Guangdong Yihao \\ Foodstuff Co., Ltd., Zhanjiang, China
}

The purpose of this study was to investigate the effects of fermented spent mushroom substrates (FSMS) on growth performance, serum biochemical, gut digestive enzyme activity, microbial community, genes expression of tight junction proteins, and volatile fatty acids in the hindgut (colon and cecum) of weaned piglets. A total of 100 weaned Yihao native pigs (native $\times$ Duroc, 50 males and 50 females) were allocated to two groups with five replicates and 10 pigs per replicate. Pigs in the control group were fed a basal diet (BD group), and the others were fed basal diets supplemented with 3\% FSMS (FSMS group). Relative to the BD group, it had better results for final weight, average daily gain, and feed conversion ratio in the FSMS group but not significant $(p>0.05)$, which was accompanied by improved serum triiodothyronine, immunoglobulin $G$, and immunoglobulin A $(p<0.05)$ but lower serum total protein, albumin, total cholesterol, and total triglyceride during the overall period $(p<0.05)$. Similarly, FSMS significantly upregulated $(p<0.05)$ the messenger RNA expression of duodenal tight junction proteins such as tight junction protein 1, tight junction protein 2, and occludin. Meanwhile, isobutyric acid, valeric acid, and isovaleric acid levels were increased, whereas propanoic acid was decreased $(p<0.05)$ in the FSMS group than the BD group. In addition, the piglets in the FSMS group changed the microbial diversity in the colon and cecum. 16S rRNA gene sequencing-based compositional analysis of the colonic and cecal microbiota showed differences in the relative abundance of bacterial phyla (Firmicutes, Bacteroidetes, etc.), genus (Lactobacillus, Streptococcus, Roseburia, etc.), and species (Lactobacillus gasseri, Clostridium disporicum, etc.) between the BD and FSMS fed piglets. In conclusion, dietary supplementation with FSMS benefited to the intestinal mucosal barrier, immunity, and composition of the microbiota.

Keywords: fermented spent mushroom substrates, weaned piglets, intestinal health, microbiota, immunity 


\section{INTRODUCTION}

Early weaning is a widespread practice in modern settings of pig production. At that time, piglets are exposed to a variety of stressors, including abrupt separation from sow and changes in diet and environment, which jointly result in a period of transient anorexia, gut mucosal atrophy, changes in intestinal microbiota composition, and weakening of immune system (1-3). Due to lack of a fully functional immune system, before, 5-6-week-old and weaned piglets are highly susceptible to multitudinous stressors leading to increase pathogenic bacteria and affecting intestinal health even death (4-6).

Antibiotics have long been used to solve problems in the weaning period and to promote the growth and health of piglets (7). Nonetheless, their indiscriminate use and misuse have led to antibiotic resistance and are potentially dangerous to human health $(8,9)$. In this scenario, there were reports that probiotics can be used as a substitute to in-feed antibiotics (10).

Probiotic defined as "live micro-organisms which when administered in adequate amounts confer a health benefit on the host" has gained much attention in recent years. It helps to relieve weaning stress, regulate intestinal flora, moreover, reduce diarrhea, etc. $(8,11)$. The Bacillus genus, a spore-forming bacterium, appears to be more resistant to adverse environments than most others and often used as porcine probiotic (12). It has been reported to reduce the number of intestinal toxigenic Escherichia coli, the incidence of diarrhea, and the mortality of weaned piglets and increase the immune effect (13). In addition, an effective probiotics administration is microbial fermentation of the feed (14).

Mushrooms have been used as food or medicine for thousands of years. Several bioactive constituents have been isolated from mushrooms, including small molecule compounds, polysaccharides, proteins, polysaccharide-protein complexes, etc. (15-17). Bioactive proteins include lectins, fungal immunomodulatory proteins, ribosome-inactivating proteins, antimicrobial proteins, ribonucleases, and laccases, which have attracted widespread attention of scientists due to their pharmaceutical potential (18-20). At present, many reports have proposed mushrooms as a feed ingredient directly to the animal diet or a small amount of it as a functional additive $(21,22)$. However, there are few reports in which the mushrooms is fermented firstly and then used as the main ingredient of the diets of livestock and poultry.

Fermented spent mushroom substrates (FSMS) is a large byproduct of local food processing, produced by Bacillus subtilis fermentation of mushrooms, which is rich in mushroom small peptide, microbial bacteria, and their metabolites. FSMS was added to the diet of weaned piglets to explore its effects on growth performance, serum biochemical parameters, digestive enzyme activity, volatile fatty acids (VFAs), and microbial community. In addition, the messenger RNA (mRNA) expression of tight junction protein 1 (TJP1), tight junction protein 2 (TJP2), and occludin (OCLN) in the duodenum was evaluated to study the effects of FSMS on intestinal mucosal permeability of piglets.

\section{MATERIALS AND METHODS}

\section{Animal Ethics Statement}

The experimental proposals and procedures for the care and treatment of the pigs were approved by the Animal Care and Use Committee of Foshan University, which were in accordance with ethical standards in Laboratory Animal-Guideline for ethical review of animal welfare (The National Standard of the People's Republic of China GB/T 35892-2018).

\section{Animals}

One hundred weaned Yihao native pigs (native $\times$ Duroc) with the same genetic background, the same batch, and normal growth and development (males and females, weaned on 26 days of age, $4.10 \pm 0.44 \mathrm{~kg}$ ) were randomly assigned to two groups with five replicates and 10 pigs per replicate. Pigs in the control group were fed a basal diet (BD group), and the others were fed basal diets supplemented with 3\% FSMS (FSMS group). All piglets were in a closed pigpen, the temperature was maintained at 25$30^{\circ} \mathrm{C}$, and relative humidity was between 65 and $75 \%$ during the experimental period. The diets and water were provided with ad libitum throughout the 33-day feeding trial. At the same time, the pig house and trough were cleaned on time every day. Management and prevention of the epidemic were carried out in accordance.

\section{Diets}

The experimental diets were formulated to meet or exceed the nutrient recommendations for lean-fat type growing-finishing pig in China (Table 1) (NY/T65, 2004). An experimental diet (FSMS) was formulated by adding 3\% FSMS into the control diet. Diets BD and FSMS were identical with respect to all nutrients with restrictions in the linear programming formulation, thus providing equal amounts of the most important nutrients.

\section{Measurement of Growth Performance Index}

The feed consumption per pen was recorded every day to calculate the average daily feed intake. The body weight (BW) of all pigs was recorded at the beginning and the end of the study period to determine average daily gain (ADG).

\section{Determination of Serum Biochemical Parameters}

At the end of the experiment, six pigs from each group ( $n$ $=6$ barrows, based on the average BW in each pen) were selected and then sampled. After fasting for approximately $12 \mathrm{~h}$, blood samples were collected by cardiac puncture, and sera were isolated by centrifugation at $3,000 \mathrm{rpm}$ for $10 \mathrm{~min}$. The levels of immunoglobulin (Ig) proteins (IgG, IgA), thyroxine (T3, T4), and insulin-like growth factor (insulin-like growth factor 1) were determined using commercially available swine enzymelinked immunosorbent assay kits from Shanghai Enzyme-linked Biotechnology Co., Ltd, China. Total protein (TP), albumin (ALB), total cholesterol (TC), triglyceride (TG), and urea (blood urea nitrogen) kits were purchased from Nanjing Jiancheng Bioengineering Research Institute, China. 
TABLE 1 | Composition and nutrient levels of the diets (\%, as-fed basis).

\begin{tabular}{|c|c|c|}
\hline \multirow[t]{2}{*}{ Items } & \multicolumn{2}{|c|}{ Diet } \\
\hline & BD & FSMS \\
\hline \multicolumn{3}{|l|}{ Ingredients (\%) } \\
\hline Fermented Lentinula edodes residue & & 3.00 \\
\hline Corn (for suckling pigs) & 38.00 & 36.86 \\
\hline Extruded corn & 24.00 & 23.28 \\
\hline Whey powder & 10.00 & 9.70 \\
\hline Soybean meal & 11.00 & 10.67 \\
\hline Fermented soybean meal & 9.00 & 8.73 \\
\hline Fish meal & 4.00 & 3.88 \\
\hline premix & 4.00 & 3.88 \\
\hline \multicolumn{3}{|l|}{ Calculated nutrient content } \\
\hline DE (kcal/kg) & $3,403.18$ & $3,401.46$ \\
\hline Crude protein (\%) & 18.91 & 18.90 \\
\hline Crude fiber (\%) & 1.98 & 2.16 \\
\hline Lysine (\%) & 1.03 & 1.00 \\
\hline Methionine (\%) & 0.34 & 0.33 \\
\hline$M+C(\%)$ & 0.65 & 0.63 \\
\hline Threonine (\%) & 0.74 & 0.72 \\
\hline Tryptophan (\%) & 0.22 & 0.21 \\
\hline
\end{tabular}

Provided per kilogram of complete diet: vitamin A, 25,000 IU; vitamin D3, 75,000 IU; vitamin E, $350 \mathrm{mg}$; vitamin K3, $150 \mathrm{mg}$; niacin, $700 \mathrm{mg}$; D-pantothenate, $520 \mathrm{mg}$; vitamin B2, $170 \mathrm{mg}$; vitamin B6, $100 \mathrm{mg}$; vitamin B12, $1 \mathrm{mg}$; folic acid, $170 \mathrm{mg}$; D-biotin, $1.7 \mathrm{mg}$; choline chloride, $400 \mathrm{mg} ; \mathrm{Mn}\left(\mathrm{MnSO}_{4} . \mathrm{H} 2 \mathrm{O}\right), 7.5 \mathrm{~g} ; \mathrm{Fe}\left(\mathrm{FeSO}_{4} . \mathrm{H} 2 \mathrm{O}\right), 10 \mathrm{~g} ; \mathrm{Zn}$ $\left(\mathrm{ZnSO}_{4} . \mathrm{H} 2 \mathrm{O}\right), 75 \mathrm{~g}$; $\mathrm{Cu}\left(\mathrm{CuSO}_{4} .5 \mathrm{H} 2 \mathrm{O}\right), 8 \mathrm{~g}$; I (KI), $50 \mathrm{mg}$; Se $\left(\mathrm{Na}_{2} \mathrm{SeO}_{3}\right), 30 \mathrm{mg}$.

Nutritional components of fermented spent mushroom substrates (FSMS): estimated DE, 3,346 kcal/kg; crude protein, $18.5 \%$; crude fiber, $8 \%$; small peptide, $8.93 \%$; lysine, $0.66 \%$; methionine, 0.2\%; threonine, 0.62\%; tryptophan, 0.73\%; valine, $0.96 \%$; leucine, $1.12 \%$.

\section{Determination of Digestive Enzyme Activity} After fasting for $\sim 12 \mathrm{~h}$, the pigs were euthanized by electrical stunning and exsanguination. The digesta of the duodenum, jejunum, ileum, cecum, and colon were collected and homogenized. Digestive enzyme activities (trypsin, lipase, $\alpha$-amylase, and $\beta$-amylase) of the contents from the duodenum were measured by using appropriate kits (Jiancheng Bioengineering, Nanjing, China).

\section{Expression of Genes Related to Intestinal Permeability}

Scraping mucosa was scraped with a cutter blade, transferred to a 2-ml centrifuge tube, and immersed in 1-ml RNA later. Total mRNAs were extracted from the mucosa by traditional Trizol method and then reversely transcribed to complementary DNAs according to the manufacturer's instructions with HiScript ${ }^{\circledR}$ II Q RT SuperMix for quantitative polymerase chain reaction (PCR) (+gDNA wiper) from Vazyme Biotech Co., Ltd., China.

Real-time reverse transcription PCR was carried out using a Power SYBR ${ }^{\circledR}$ Green PCR Master Mix (Promega, American) with a QuantStudio 3 Real-Time PCR System (Applied Biosystems; Thermo Fisher Scientific, Inc.). The PCR cycling condition was as follows: one cycle at $95^{\circ} \mathrm{C}$ for $5 \mathrm{~min}$, then 40 cycles of $95^{\circ} \mathrm{C}$ for $15 \mathrm{~s}, 58 / 59^{\circ} \mathrm{C}$ for $40 \mathrm{~s}, 72^{\circ} \mathrm{C}$ for $15 \mathrm{~s}$, and melt curve at $58 / 59^{\circ} \mathrm{C}$ for $1 \mathrm{~min}, 95^{\circ} \mathrm{C}$ for $15 \mathrm{~s}$. For each sample, reactions were duplicated, and the average mRNA expression level of each gene was normalized to the reference gene $\beta$ actin level and determined using the $2^{-\Delta \Delta \mathrm{Ct}}$ method. The primer pairs for measuring the levels of each gene are listed in Supplementary Table 1.

\section{Determination of Volatile Fatty Acids}

For determination of VFAs, according to steps described in Effect of tea saponin on rumen fermentation in vitro (23), $10 \mathrm{~g}$ of colon digesta was placed in centrifugal tubes, mixed uniformly with $10 \mathrm{ml}$ of $25 \%$ ortho-phosphoric acid and then centrifuged at $10,000 \mathrm{rpm}$ for $10 \mathrm{~min}$. The supernatant was decanted into another test tube, capped, and stored in a refrigerator at $4^{\circ} \mathrm{C}$ until analyzed using gas chromatography (SP-3420, Beijing Analysis Instrument Factory). The supernatant was filtered through a $0.22-\mu \mathrm{m}$ membrane and then injected into a $2 \times 6-\mathrm{mm}$ glass column packed with Chromosorb (80-100 mesh). The temperature of the injector/detector and the column were 260 and $220^{\circ} \mathrm{C}$, respectively. Nitrogen was used as a carrier.

\section{Microbial Community}

Fecal samples from cecum and colon were collected and transferred to a 2-ml centrifuge tube and immersed in 1-ml RNA later. Microbial DNA extraction was performed using a QIAamp DNA Stool Mini Kit (QIAGEN, Germany) according to manufacturer's protocol. DNA concentrations of every sample were quantified using a Nanodrop 2000 spectrophotometer (Thermo Fisher Scientific, Wilmington, DE, United States). The genes of all bacterial 16S rRNA in the region of V3-V4 were amplified by PCR using a universal forward primer $338 \mathrm{~F}\left(5^{\prime}\right.$ ACTCCTRCGGGAGGCAGCAG-3') and a reverse primer 806R (5'-GGACTACCVGGGTATCTAAT-3') (24). PCR reactions were carried out in $30-\mu 1$ reactions with $15 \mu$ l of Phusion High-Fidelity PCR Master Mix (New England Biolabs), $0.2 \mu \mathrm{M}$ of forward and reverse primers, and 10-ng template DNA. Thermal cycling consisted of initial denaturation at $98^{\circ} \mathrm{C}$ for $1 \mathrm{~min}$, followed by 30 cycles of denaturation at $98^{\circ} \mathrm{C}$ for $10 \mathrm{~s}$, annealing at $50^{\circ} \mathrm{C}$ for $30 \mathrm{~s}$, and elongation at $72^{\circ} \mathrm{C}$ for $30 \mathrm{~s}$, finally $72^{\circ} \mathrm{C}$ for $5 \mathrm{~min}$.

The authors mixed the same volume of $1 \times$ loading buffer (contained SYB green) with PCR products and operate electrophoresis on $2 \%$ agarose gel for detection. PCR products were mixed in equidensity ratios. Then, mixture PCR products were purified with the Qiagen Gel Extraction Kit (Qiagen, Germany). Sequencing libraries were generated using Illumina TruSeq DNA PCR-Free Library Preparation Kit (Illumina, USA) following the manufacturer's recommendations, and index codes were added. The sequences were performed by Illumina Hiseq platform (NovoGene Ltd and Biomarker Ltd., respectively).

The QIIME (version 1.9.1, http://qiime.org/scripts/split_ libraries_fastq.html) software package was used to demultiplex and quality-filter raw sequence data generated from $16 \mathrm{~S}$ rRNA MiSeq sequencing (25). Gaps in each sequence were discarded from all the samples to decrease the noise generated by the screening, filtering, and pre-clustering processes, as described previously (26). Operational taxonomic units (OTUs) were clustered as a similarity cutoff of $97 \%$ using UPARSE 
(version 7.0.1001, http://drive5.com/uparse/), and unnormal gene sequences were identified and deleted using UCHIME (27). With each OTU, the representative sequence was analyzed using the Ribosomal Database Project classifier (RRID: SCR_006633) against the Silva (http://www.arb-silva.de/) 16S rRNA database using a confidence level of $90 \%$.

The bacterial diversity, such as rarefaction analysis, the number of observed OTUs, coverage abundance estimator, richness estimator (Chao 1 and ACE), and diversity indices (Shannon and Simpson), were calculated using MOTHUR software (version 1.35.12) according to previous instructions (28).

\section{Statistics}

Where appropriate, results were analyzed using an unpaired, two-tailed Student's $t$-test (TTEST function in Microsoft Excel $2007)$ to calculate a $p$-value. Values $<0.05$ were deemed statistically significant.

\section{RESULTS}

\section{Growth Performances}

The influences of adding FSMS on pig growth performance are shown in Table 2. There are 50 piglets in each group, and no significant differences were noted for the initial weight. In addition, compared with the $\mathrm{BD}$ group, there were no significant differences between the two groups for the final weight, ADG, and FCR in the FSMS group over the entire feeding period $(p>0.05)$.

\section{Serum Biochemical Parameters}

The influences of FSMS addition on porcine blood biochemical indexes are shown in Table 3. IgG, IgA, and T3 were all significantly higher in the FSMS group $(p<0.05)$. In parallel with this, the content of TP, ALB, TC, and TG in the FSMS group were significantly decreased $(p<0.05)$. However, there was no significant difference between the two groups for the T4, insulinlike growth factor 1 , and blood urea nitrogen over the entire feeding period $(p>0.05)$.

\section{Digestive Performance}

The influences of FSMS addition on porcine duodenum content digestive enzyme activities are shown in Table 4. Over the entire 33 -day growth trial, the trypsin, lipase, $\alpha$-amylase, and $\beta$-amylase of piglets in the FSMS group had no significant difference from the BD group.

TABLE 2 | Influence of FSMS addition on porcine growth performance indexes.

\begin{tabular}{lccc}
\hline Items & BD & FSMS & p-value \\
\hline Sample & 50 & 50 & \\
Initial weight $(\mathrm{kg})$ & $4.15 \pm 0.45$ & $4.05 \pm 0.43$ & 0.898 \\
Final weight $(\mathrm{kg})$ & $14.69 \pm 1.29$ & $15.08 \pm 1.06$ & 0.836 \\
ADG $(\mathrm{g})$ & $301.28 \pm 24.86$ & $315.00 \pm 18.01$ & 0.816 \\
FCR & $1.33 \pm 0.02$ & $1.29 \pm 0.01$ & 0.092 \\
\hline
\end{tabular}

\section{Gene Expression of Tight Junction Proteins}

The expression of genes related to intestinal permeability in the duodenum is shown in Figure 1. According to the results, the addition of FSMS in the diet of weaned piglet significantly upregulated the expression of TJP1, TJP2, and OCLN genes in the duodenum $(P<0.05)$.

\section{Volatile Fatty Acids}

The effects of different dietary treatments on colonic content VFA are as presented in Table 5. The piglets in the FSMS group showed a lower propanoic acid than those in the BD group $(P<$ $0.05)$. The contents of isobutyric acid, valeric acid, and isovaleric acid in the FSMS group were significantly higher than those in the BD group $(P<0.05)$. Additionally, there was no significant difference in the content of acetic acid and butyric acid between the two groups $(P>0.05)$.

\section{Microbial Community}

To evaluate the impact of FSMS addition on the microbial composition of cecal and colonic digesta, a total of 1,463,611 V3-V4 16S rRNA effective sequences from the 24 samples (12 cecal digesta samples and 12 colonic digesta samples), with an average of 60,984 sequences per sample, were used for subsequent analysis.

TABLE 3 | Influence of FSMS addition on porcine blood biochemical indexes.

\begin{tabular}{lccc}
\hline Items & BD & FSMS & $\boldsymbol{p}$-value \\
\hline $\mathrm{lgG}(\mathrm{mg} / \mathrm{ml})$ & $21.4 \pm 2.86^{\mathrm{b}}$ & $32.23 \pm 3.39^{\mathrm{a}}$ & 0.001 \\
$\mathrm{lgA}(\mathrm{ug} / \mathrm{ml})$ & $679.06 \pm 140.27^{\mathrm{b}}$ & $866.00 \pm 50.21^{\mathrm{a}}$ & 0.026 \\
$\mathrm{~T} 3(\mathrm{pmol} / \mathrm{L})$ & $11.52 \pm 1.94^{\mathrm{b}}$ & $14.73 \pm 1.69^{\mathrm{a}}$ & 0.017 \\
$\mathrm{~T} 4(\mathrm{pmol} / \mathrm{L})$ & $45.71 \pm 4.98$ & $50.47 \pm 2.71$ & 0.108 \\
$\mathrm{IGF}-1(\mathrm{ng} / \mathrm{ml})$ & $595.19 \pm 72.79$ & $754.35 \pm 148.68$ & 0.103 \\
$\mathrm{TP}(\mathrm{mg} / \mathrm{ml})$ & $66.39 \pm 10.05^{\mathrm{a}}$ & $49.61 \pm 7.43^{\mathrm{b}}$ & 0.017 \\
$\mathrm{ALB}(\mathrm{g} / \mathrm{L})$ & $30.13 \pm 7.12^{\mathrm{a}}$ & $21.06 \pm 1.94^{\mathrm{b}}$ & 0.025 \\
$\mathrm{TC}(\mathrm{mmol} / \mathrm{L})$ & $7.69 \pm 1.89^{\mathrm{a}}$ & $5.46 \pm 0.87^{\mathrm{b}}$ & 0.049 \\
$\mathrm{TG}(\mathrm{mmol} / \mathrm{L})$ & $4.37 \pm 2.17^{\mathrm{a}}$ & $1.62 \pm 0.37^{\mathrm{b}}$ & 0.023 \\
$\mathrm{BUN}(\mathrm{mmol} / \mathrm{L})$ & $4.03 \pm 0.45$ & $3.73 \pm 0.73$ & 0.470 \\
\hline
\end{tabular}

IgG, immunoglobulin $G$; IgA, immunoglobulin $A$; T3, triiodothyronine; T4, tetraiodothyronine; IGF-1, insulin-like growth factor 1; TP, total protein; $A L B$, albumin; TC, total cholesterol; TG, triglyceride; BUN, blood urea nitrogen. Values are means \pm SEM $(n=6)$. Results were analyzed by $t$-test, and the variant letter in the same row indicated a significant difference when $P<0.05$.

TABLE 4 | Influence of FSMS addition on porcine duodenum content digestive enzyme activities.

\begin{tabular}{lccc}
\hline Items & BD & FSMS & p-value \\
\hline Trypsin $(\mathrm{U} / \mathrm{mg})$ & $12.71 \pm 8.05$ & $46.32 \pm 37.89$ & 0.200 \\
Lipase $(\mathrm{U} / \mathrm{g})$ & $203.31 \pm 203.59$ & $214.87 \pm 45.03$ & 0.915 \\
$\alpha$-Amylase $(\mathrm{mmol} / \mathrm{L})$ & $6264.89 \pm 389.63$ & $5846.31 \pm 641.09$ & 0.328 \\
$\beta$-Amylase $(\mathrm{mmol} / \mathrm{L})$ & $79.06 \pm 11.89$ & $79.81 \pm 5.32$ & 0.901 \\
\hline
\end{tabular}

Values are means \pm SEM $(n=6)$. Results were analyzed by the $t$-test, and the variant letter in the same row indicated a significant difference when $P<0.05$. 


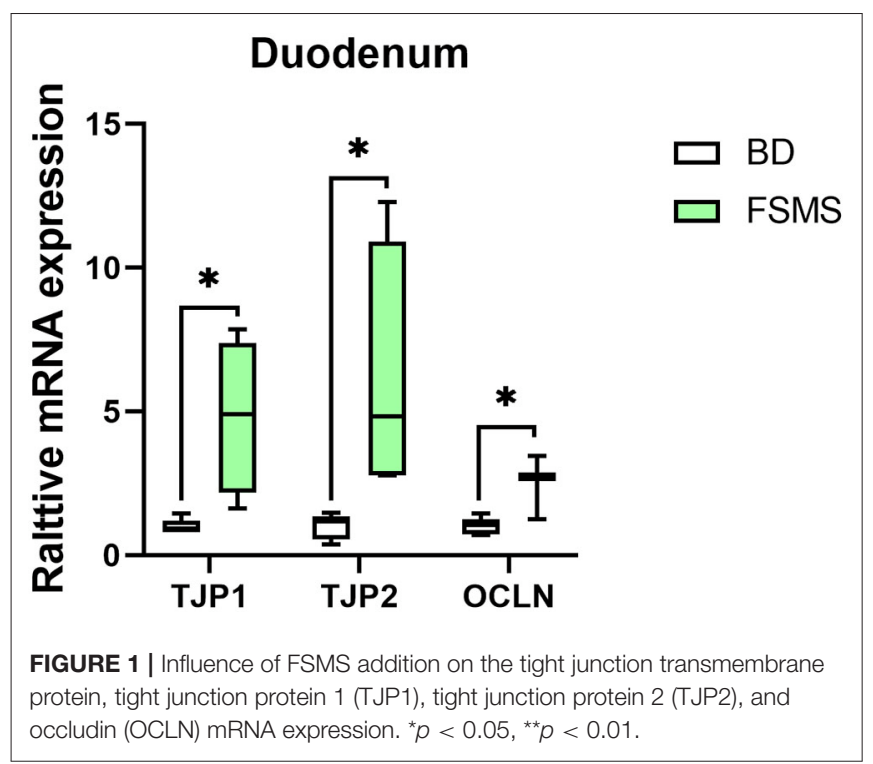

TABLE 5 | Influence of FSMS addition on porcine colon digesta volatility fatty acids (VFAs) production.

\begin{tabular}{lccc}
\hline Items & BD & FSMS & p-value \\
\hline Acetic acid (mmol/L) & $59.59 \pm 5.78$ & $50.93 \pm 11.03$ & 0.170 \\
Propanoic acid (mmol/L) & $26.16 \pm 1.74^{\mathrm{a}}$ & $19.38 \pm 6.55^{\mathrm{b}}$ & 0.036 \\
Butyric acid (mmol/L) & $5.99 \pm 0.84$ & $4.37 \pm 1.28$ & 0.056 \\
Isobutyric acid (mmol/L) & $0.38 \pm 0.17^{\mathrm{b}}$ & $1.95 \pm 0.33^{\mathrm{a}}$ & 0.000 \\
Valeric acid (mmol/L) & $0.78 \pm 0.12^{\mathrm{b}}$ & $1.34 \pm 0.53^{\mathrm{a}}$ & 0.050 \\
Isovaleric acid (mmol/L) & $0.62 \pm 0.13^{\mathrm{b}}$ & $2.58 \pm 0.50^{\mathrm{a}}$ & 0.000
\end{tabular}

Values are means \pm SEM $(n=6)$. Results were analyzed by the t-test, and the variant letter in the same row indicated a significant difference when $P<0.05$.

The influences of FSMS addition on porcine cecal digesta bacterial community are shown in Supplementary Table 2. Diversity indices and richness were analyzed to compare the differences in alpha diversity of microorganisms in cecum between the FSMS group and the BD group. Piglets in the FSMS group had higher diversity indices compared with those in the BD group, as reflected by the Shannon index with statistical differences $(p<0.05)$ but without affecting OUT numbers and Simpson index $(p>0.05)$. Curiously, for observed species, Chao1 and ACE, the BD group is significantly higher than the FSMS group $(p<0.05)$.

The influences of FSMS addition on porcine colonic digesta bacterial community are shown in Supplementary Table 3. Piglets in the FSMS group had a higher observed species and Shannon indices compared with those in the BD group $(p<$ $0.05)$. However, no differences in OUT numbers, Goods coverage, Chaol, ACE, and Simpson index between the two groups were observed $(p>0.05)$.

The influences of FSMS addition on the porcine relative abundance of bacterial phylum in the cecal digesta are shown in Figure 2. A total of 10 different phyla were detected in the examined samples. The two groups showed very similar taxonomic compositions at the phylum-level distributions, and the major sequences obtained from the samples belonged to Firmicutes and Bacteroidetes, contributing 43.58 and $45.46 \%$ in the FSMS group and 48.20 and $46.36 \%$ in the BD group, respectively (Figure 2A). Piglets in the FSMS group demonstrated a significantly decreased $(P<0.05)$ abundance of bacteria belonging to the phyla Actinobacteria compared with the piglets in the $\mathrm{BD}$ group, whereas a significant increased $(P<0.05)$ abundance of Proteobacteria, Spirochaetes, Fibrobacteres, and Chlamydine compared with the pigs in the BD group (Figure 2B).

The influences of FSMS addition on the porcine relative abundance of bacterial phylum in the colonic digesta are shown in Figure 3. A total of 10 different phyla were detected in the examined samples. The two groups showed very similar taxonomic compositions at the phylum-level distributions, and the major sequences obtained from the samples belonged to Firmicutes and Bacteroidetes, contributing 54.02 and $34.52 \%$ in the FSMS group and 40.79 and $53.20 \%$ in the BD group, respectively (Figure 3A). Compared with the piglets in the $\mathrm{BD}$ group, piglets in the FSMS group demonstrated a significantly decreased $(P<0.01)$ abundance of bacteria belonging to the predominant phyla Bacteroidetes, whereas a significant increased $(P<0.05)$ abundance of Firmicutes, Proteobacteria, Spirochaetes, Tenericutes, unidentified bacteria, Fibrobacteres, and Actinobacteria compared with the pigs in the BD group (Figure 3B).

The influences of FSMS addition on the porcine relative abundance of the bacterial genus in the cecal digesta are shown in Figure 4. A total of 10 different phyla were detected in the examined samples. The two groups showed very similar taxonomic compositions at the genus-level distributions, but the major sequences obtained from the samples belonged to Lactobacillus and Alloprevotella in the FSMS group, contributing 10.73 and $6.20 \%$, respectively, whereas the predominant genera were Lactobacillus and unidentified Prevotellaceae in the $\mathrm{BD}$ group, contributing 18.24 and 3.57\%, respectively (Figure 4A). Compared with the piglets in the BD group, the piglets in the FSMS group demonstrated a significantly decreased $(P<0.01)$ abundance of bacteria belonging to the predominant genera Lactobacillus, whereas a significantly increased $(P<0.05)$ abundance of Streptococcus, unidentified Prevotellaceae, Ruminobacter, Roseburia, and unidentified Clostridiales (Figure 4B).

The influences of FSMS addition on the porcine relative abundance of the bacterial genus in the colonic digesta are shown in Figure 5. A total of 10 different phyla were detected in the examined samples. The two groups showed very similar taxonomic compositions at the genus-level distributions, but the major sequences obtained from the samples belonged to Lactobacillus and Alloprevotella in the FSMS group, contributing 14.17 and $4.43 \%$, respectively, whereas the predominant genera were Lactobacillus and unidentified Prevotellaceae in the $\mathrm{BD}$ group, contributing 10.94 and 5.22\%, respectively (Figure 5A). Compared with the piglets in the $\mathrm{BD}$ group, the piglets in the FSMS group demonstrated a significantly decreased $(P<0.01)$ abundance of bacteria belonging to the predominant genera 

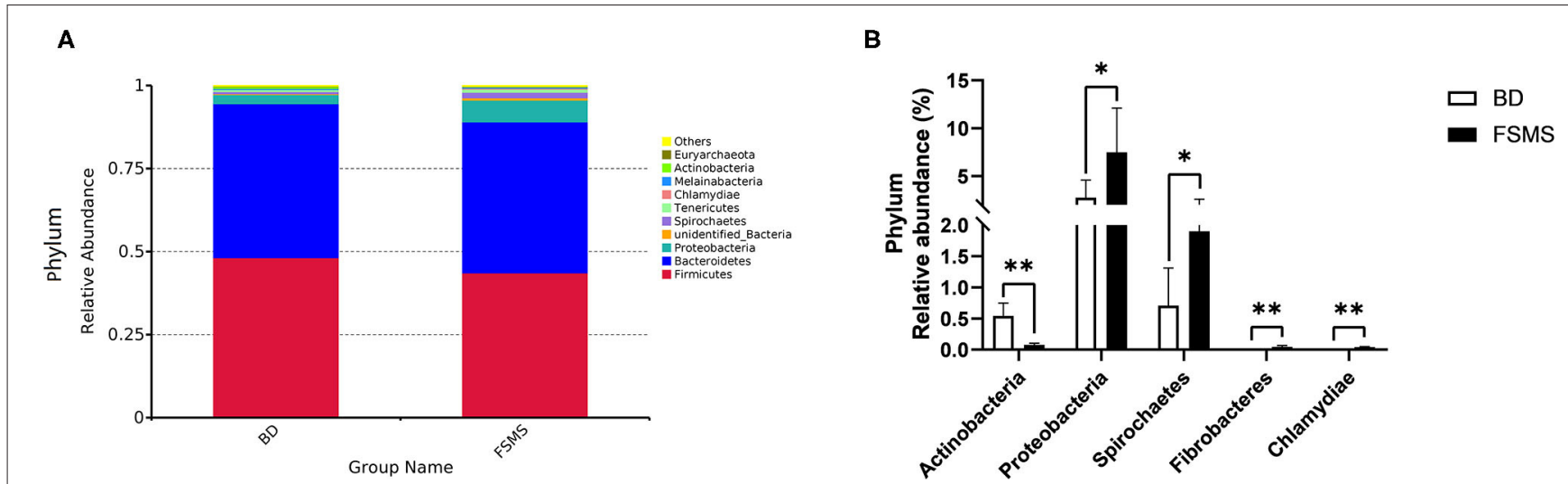

FIGURE 2 | Relative abundance of bacterial phylum in the cecal digesta of pigs (A). Significantly changed phyla in the cecal digesta (B). Values were expressed as means \pm SEM $(n=6)$. Statistical differences were calculated by Duncan: ${ }^{\star} p<0.05,{ }^{\star \star} p<0.01$.
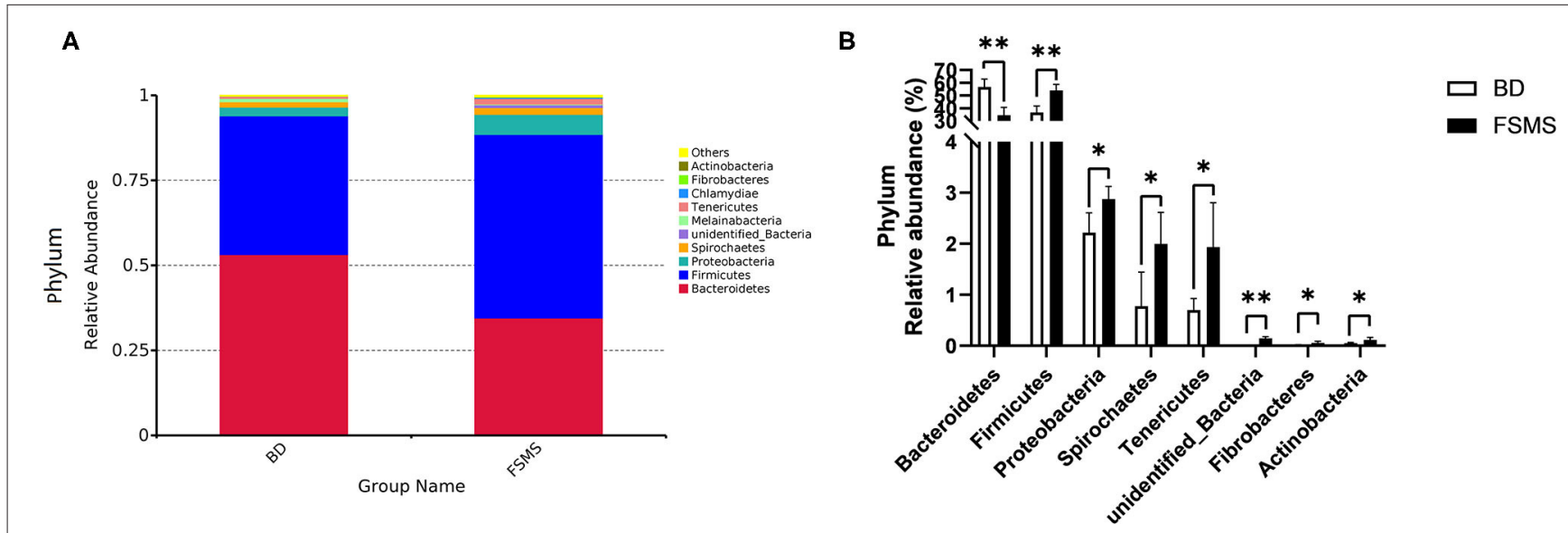

FIGURE 3 | Relative abundance of bacterial phylum in the colonic digesta of pigs (A). Significant changed phyla in the colonic digesta (B). Values were expressed as means $\pm \operatorname{SEM}(n=6)$. Statistical differences were calculated by Duncan: ${ }^{*} p<0.05,{ }^{* \star} p<0.01$.

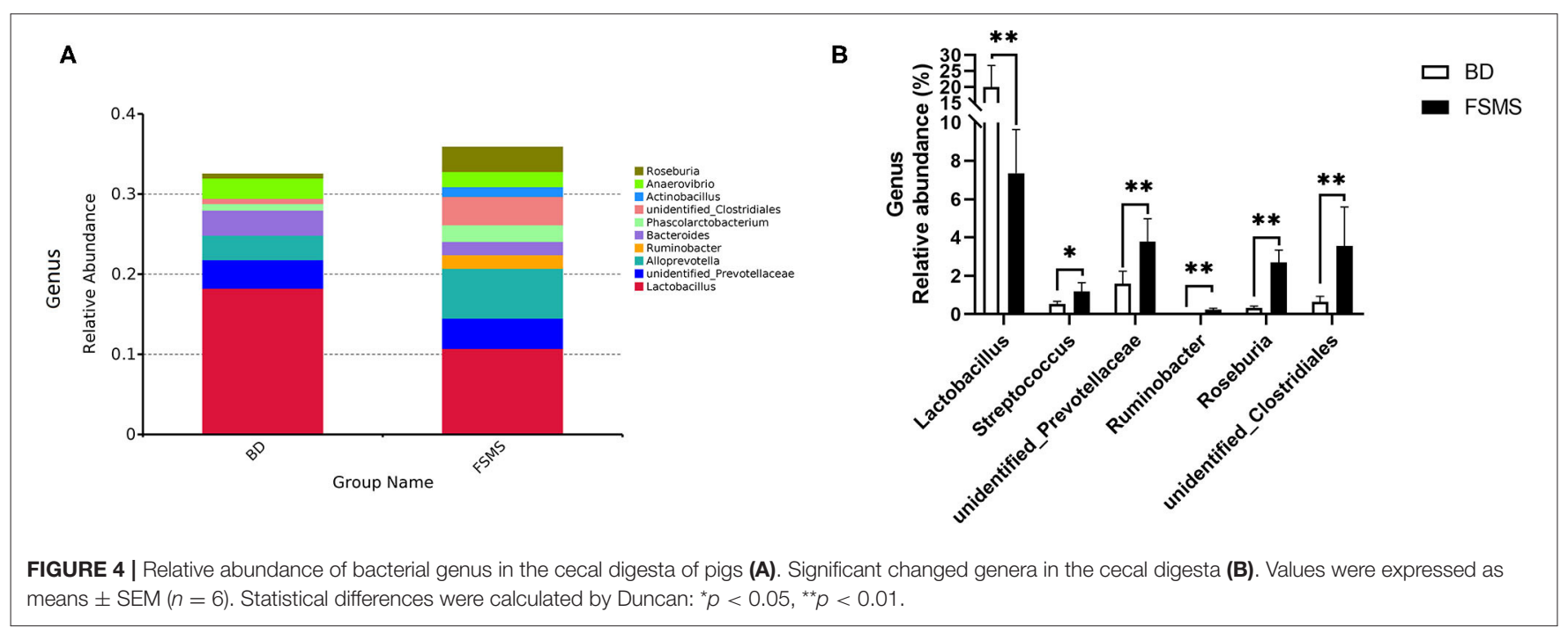


Parabacteroides, whereas a significant increased $(P<0.05)$ abundance of Lactobacillus, Streptococcus, and unidentified Clostridiales (Figure 5B).

The influences of FSMS addition on the porcine relative abundance of bacterial species in the cecal digesta are shown in Figure 6. A total of 10 different species were detected in the examined samples. The two groups showed very similar taxonomic compositions at the species-level distributions, but the major sequences obtained from the samples belonged to Lactobacillus gasseri and Roseburia faecis in the FSMS group, contributing 5.38 and $2.84 \%$, respectively, whereas the predominant genera were L. gasseri and unidentified Prevotellaceae in the BD group, contributing 10.02 and $2.46 \%$, respectively (Figure 6A). Compared with the piglets in the $\mathrm{BD}$ group, the piglets in the FSMS group demonstrated a significantly decreased $(P<0.01)$ abundance of bacteria belonging to L. gasseri and Lactobacillus reuteri, whereas a significant increased $(P<0.05)$ abundance of Lactobacillus amylovorus, $R$. faecis, bacterium mpn-isolate group 2, Clostridium disporicum, (Haemophilus) parasuis, and Campylobacter coli (Figure 6B).

The influences of FSMS addition on the porcine relative abundance of bacterial species in the colonic digesta are shown in Figure 7. A total of 10 different species were detected in the examined samples. The two groups showed very similar taxonomic compositions at the species-level distributions, but the major sequences obtained from the samples belonged to $L$. gasseri and L. amylovorus in the FSMS group, contributing 7.99 and $2.80 \%$, respectively, whereas the predominant genera were L. gasseri and Porphyromonadaceae bacterium DJF B175 in the BD group, contributing 7.09 and $4.68 \%$, respectively (Figure 7A). Compared with the piglets in the BD group, the piglets in the FSMS group demonstrated a significantly decreased $(P<0.05)$ abundance of bacteria belonging to the P. bacterium DJF B175 and $E$. coli, whereas a significant increased $(P<0.05)$ abundance of L. gasseri, L. amylovorus, L. reuteri, C. disporicum, and C. coli (Figure 7B).

\section{DISCUSSION}

The intestinal barrier is vital for nutrient absorption and health in animals (29). However, various factors cause the piglets to stress and thus destroy the intestinal barrier during weaning (30). We do know antibiotics used to solve problems of piglets weaning but may lead to antibiotic resistance (31). It has been reported that probiotics can be an alternative to antibiotics and that fermented food is an ideal vehicle for the delivery of probiotics to animals. In addition, the fermented feed has antioxidant, immune, and antibacterial effects (32-35). Thus, in this study, we used FSMS to explore its effects on growth performance and intestinal health of weaned piglets.

\section{Growth Performances}

Piglet growth performance is subjected to diet ingredients. Feeding fermented feed to piglets has given varying effects on growth performance. In the present study, the growth performance of piglets fed with FSMS additional feed was improved compared with that of piglets fed the same unadded diet. This type of results has also been observed with Hanwoo steers fed diet added microbially FSMS (36). The effect of microbially FSMS addition might be an increased intake of DM and CP effects. Additionally, the favorable impact could be due to the microbes. $\mathrm{Hu}$ et al. reported that the ADG and feed efficiency of feed weaned piglets with added bacillus increased (37). Huang et al. also reported that the dietary addition of bacillus increased the BW of the weaning piglets (38). Previous research has also indicated that fermented feed improved the flavor and palatability of feed as well as decomposing nutrients and reducing the wear and tear of the intestines, which was beneficial to the absorption and makes the piglets' performance improved $(39,40)$. It is believed that feeding FSMS favorably affected the growth of piglets.

\section{Serum Parameters and Tight Junction Proteins mRNAs Expression}

Serum antibody levels are an indicator of humoral immunity, and an animal's systemic immune status may be reflected by the concentration of serum IgG (41). A previous study has documented that fermented Ginkgo biloba L. residues result in raised IgG and $\operatorname{IgA}(40)$. In this study, diet FSMS supplementation increased serum $\operatorname{IgG}$ and $\operatorname{IgA}$ of piglets by 50.05 and $27.53 \%$, respectively. This beneficial effect might be due to the mRNA upregulation of TJP. TJPs play a positive role in improving body immune state (42). The function of the intestinal mucosal barrier is to prevent intestinal flora and toxins from entering the blood circulation, playing a crucial role in the health and growth of weaned piglets. Proper epithelial function mainly depends on tight junctions (43). The gastrointestinal tract is considered the largest immunological organ in the body, having a central role in regulating immune homeostasis (44). Therefore, duodenum TJP mRNA up-expression may be one of many reasons for the increase of serum Ig levels. This means that FSMS can be specifically applied to situations aimed to enhance animal immunity.

Piglet metabolism can be reflected by various biochemical indexes in serum. Protein is an important material basis for animal metabolism, growth, and development. The content of TP in blood demonstrates the metabolic activity of the substance $(45,46)$. ALB, synthesized and secreted by the liver, is generally regarded as protein synthesis and metabolic indicators related to piglet growth performance (47). Blood cholesterol and TG levels are linked to several cardiovascular diseases and are a major cause of atherosclerosis $(48,49)$. The concentration of TG and TC in the blood is an important index to measure the metabolism of blood lipids, reflecting the development of adipose tissue and the level of fat deposition. The results of our study, a decrease in TP, ALB, TC, and TG levels, may implicate that the supplementation of FSMS can reduce the burden of protein synthesis in the liver and regulate the fat deposition, meanwhile benefiting the cardiovascular system.

T3 is a major part of the physiological role of thyroxine in animals. It is said that thyroxine can also accelerate the transformation of cholesterol into cholic acid and cholate has the role of helping fat digestion, which can reduce the content of serum cholesterol. A previous study notes that when challenged with live yeast and superfine yeast in the basic diet, T3 of piglets significantly increased $(P<0.05)$. In our study, the 


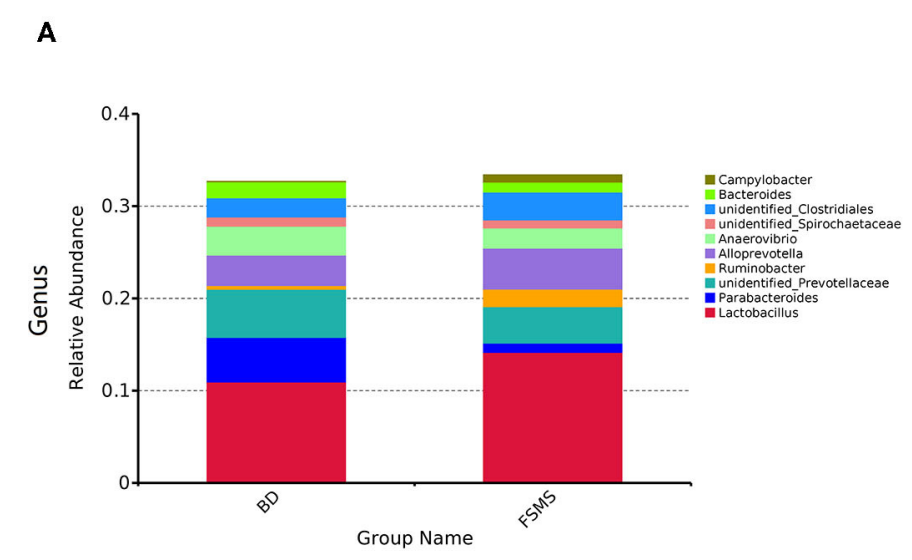

B

FIGURE 5 | Relative abundance of bacterial genus in the colonic digesta of pigs (A). Significant changed genera in the colonic digesta (B). Values were expressed as means \pm SEM $(n=6)$. Statistical differences were calculated by Duncan: ${ }^{*} p<0.05,{ }^{\star *} p<0.01$.

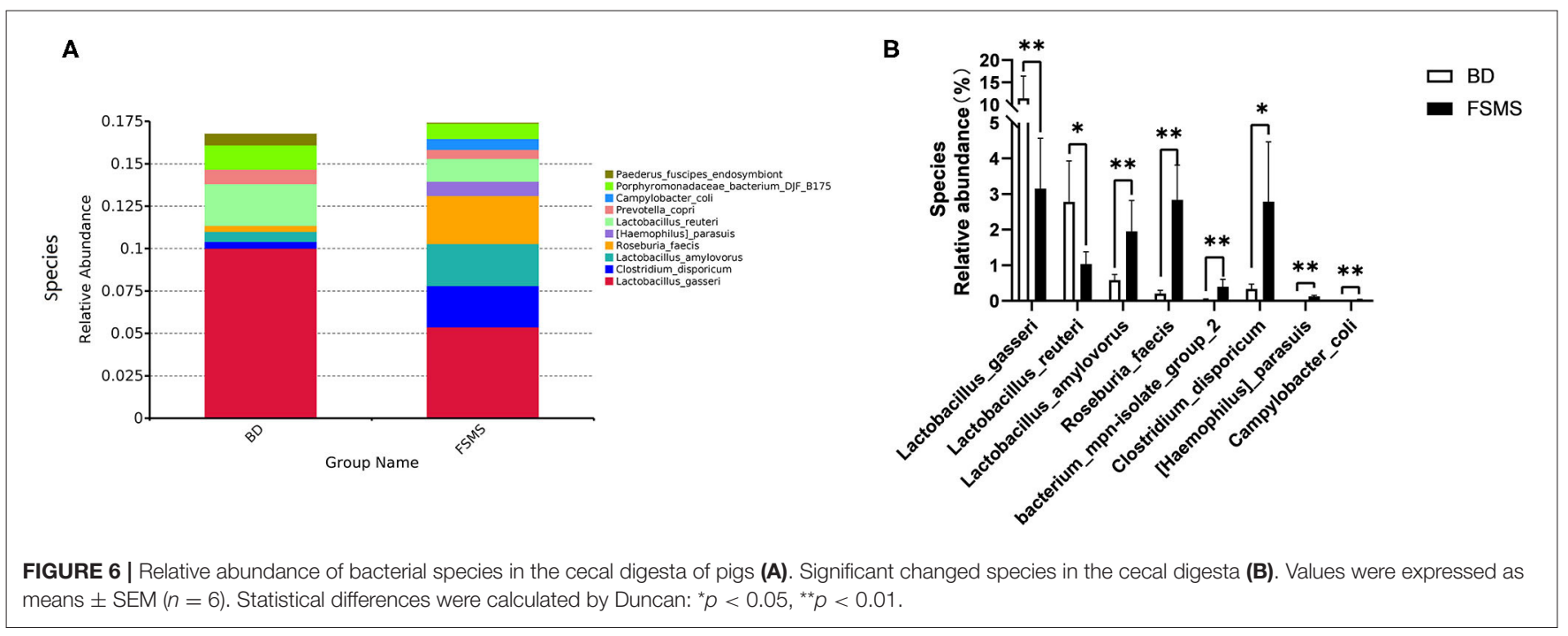

concentrations of T3 increased by $27.86 \%$ and serum cholesterol decreased by $29.00 \%$ in the FSMS group. This was in agreement with the earlier discussed literature.

\section{Volatile Fatty Acids}

The main place of pig microbial digestion is located in the back part of the digestive tract. Nutrients not absorbed by the stomach and small intestine enter the back intestine. After further fermentation by microorganisms, the fermentation products can be absorbed and enter the body to supply energy and regulate host metabolism and immunity. VFAs, including acetate, butyrate, propionate, isobutyric acid, valeric acid, and isovaleric acid, are produced mainly by microbial fermentation in the colon of mammals (50). As reported, valine and leucine were extensively metabolized within the rumen, yielding large quantities of isobutyric acids and isovaleric acid, respectively. Both amino acids tended to decrease the level of acetic acid, propanoic acid, and butyric acids (51, 52). In our study, FSMS was rich in valine $(0.96 \%)$ and leucine $(1.12 \%)$. This should be the cause of the variation of VFAs. In addition, propionate is synthesized via the succinate pathway, acrylate pathway, or propanediol pathway. This can be done by various microorganisms, including Bacteroidetes fermentation $(53,54)$. Our results showed that FSMS addition decreased the abundance of bacteria belonging to the predominant phyla Bacteroidetes in the colonic digesta. Therefore, the decrease of Bacteroidetes may also contribute to the decline in propionate.

\section{Microbial Community}

There are trillions of microbes (including fungi, viruses, and bacteria) in the mammalian intestine harbors, which play an important role in maintaining intestinal environmental stability and host health, and they are considered as an additional organ (55). Microbiota influence intestinal barrier function (56). Changes in the species richness and diversity of bacteria help in the digestion and absorption of piglets (57). Changes in diet ingredients (such as carbohydrates, probiotics, etc.) affect the composition of intestinal microbes, thereby affecting 


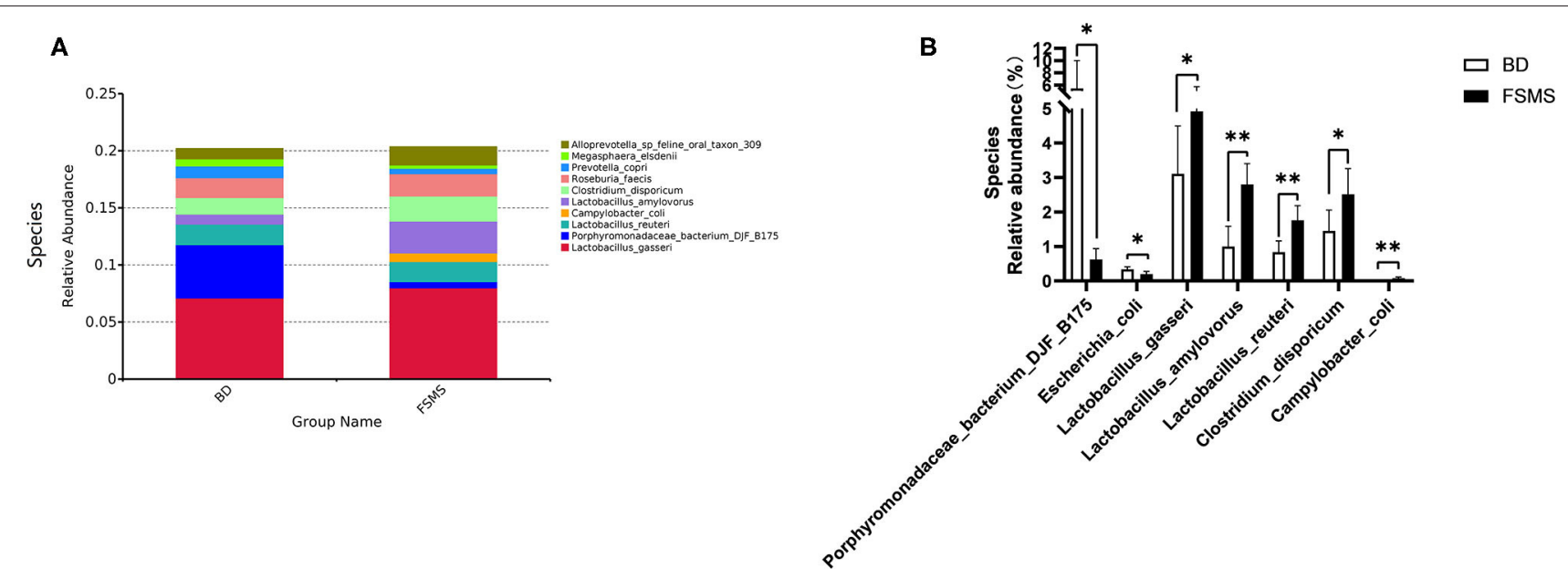

FIGURE 7 | Relative abundance of bacterial species in the colonic digesta of pigs (A). Significant changed species in the colonic digesta (B). Values were expressed as means $\pm \operatorname{SEM}(n=6)$. Statistical differences were calculated by Duncan: ${ }^{\star} p<0.05,{ }^{* \star} p<0.01$.

intestinal health (58). In a well-balanced microbial environment, members of the following genera prevail: Streptococcus, Lactobacillus, Bifidobacterium, Enterococcus, Eubacterium, Fusobacterium, Peptostreptococcus, Enterobacter, Bacteroides, and Porphyromona, whereas the number of coliform bacteria $E$. coli and Clostridium sp. is lower (59).

In this study, 16S rRNA gene sequencing-based compositional analysis of the cecal and colonic microbiota showed differences in the relative abundance of bacterial phyla, genus, and species between the BD and FSMS-fed piglets, indicating that FSMS affected the gut microbiota. Ten bacterial phyla were identified in the cecum and colon, respectively, with Firmicutes, Bacteroidetes, and Proteobacteria dominating in the colon of the FSMS piglets, which was similar to findings found by Zhengjun Xie and Han (60). Among them, Firmicutes and Proteobacteria increased, but Bacteroidetes reduced significantly in the intestine. More abundance of Proteobacteria may be more favorable for animal health. A previous study demonstrates that a flora rich in Proteobacteria produces sepsis resistance in mice mediated by serum IgA (61). This corresponds to the findings that serum IgA increased in our study. Namely, the modulation of intestinal flora resulted in enhanced immunity. At the genus level, Lactobacillus, Streptococcus, and Roseburia were more abundant in the FSMS-fed piglets. Lactobacillus, Gram-positive bacteria is a normal flora of the gastrointestinal (GI) tract, and it can promote health in humans and other mammals (62). Studies have demonstrated that Lactobacillus is beneficial to maintain the intestinal epithelial barrier function in early-weaned piglets, and that may be used for preventing intestinal damage (63). In our study, L. gasseri, L. amylovorus, and L. reuteri species were all significantly increased in the colon. Streptococcus can produce organic acids and bacteriocins, thereby reducing intestinal $\mathrm{pH}$, inhibiting the growth of pathogenic bacteria in the intestinal tract and benefit intestinal function (64). In addition, the enrichment of the genus Streptococcus in healthy infants has been reported by Zheng, and it revealed anti-inflammatory properties (65).
Roseburia, SCFA producers, acidifies the intestinal environment, thus conducive to the growth of beneficial bacteria and inhibits the proliferation of harmful bacteria $(66,67)$. Like our study, Roseburia was also enriched in the $15 \%$ fermented Mao-tai lees group (68). Moreover, the abundance of E. coli decreased after feeding an FSMS diet. Therefore, the relative abundance of some beneficial bacteria increased (Lactobacillus, Streptococcus, and Roseburia) in the FSMS group indicated that feeding of the FSMS diet might have beneficial effects on the health of pigs.

\section{CONCLUSION}

Three percent FSMS supplementation to piglets' diet can improve the composition of microbiota in the hindgut, intestinal barrier function, and overall immune status. This implies that FSMS can be used in animal diet formulation at an appropriate addition level. FSMS is a compound that contains mushroom small peptide, microbial bacteria, and their metabolites and which is the main effect component that needs to be confirmed.

\section{DATA AVAILABILITY STATEMENT}

The datasets generated for this study can be found in NCBI SRA, NCBI Accession No. PRJNA658850.

\section{ETHICS STATEMENT}

The experimental proposals and procedures for the care and treatment of the pigs were approved by the Animal Care and Use Committee of Foshan University, which were in accordance with ethical standards in Laboratory animal-Guideline for ethical review of animal welfare (The National Standard of the People's Republic of China GB/T 35892-2018). 


\section{AUTHOR CONTRIBUTIONS}

QQ and HZ conceived and designed the whole trial. MT and DC conducted the pig trial. QQ and QP conducted laboratory analyses. QQ, QP, and $\mathrm{HZ}$ wrote the manuscript. All authors contributed to the article and approved the submitted version.

\section{FUNDING}

The Project was supported by Key Projects of National Key Research and Development Program of China (Grant No. 2018YFD0501202-3), the Scientific Research Foundation in the Higher Education Institutions of Educational Commission

\section{REFERENCES}

1. Blecha F, Pollmann DS, Nichols DA. Weaning pigs at an early age decreases cellular immunity. J Anim Sci. (1983) 56:396-400. doi: $10.2527 /$ jas $1983.562396 \mathrm{x}$

2. Nuria De Diego-Cabero AMDM. Bile acid mediated effects on gut integrity and performance of early-weaned piglets. BMC Vet Res. (2015) 11:111. doi: 10.1186/s12917-015-0425-6

3. Wu Z, Feng H, Cao Y, Huang Y, Dai C, Wu S, et al. New insight into the molecular mechanism of the FUT2 regulating Escherichia coli F18 resistance in weaned piglets. Int J Mol Sci. (2018) 19:3301. doi: 10.3390/ijms19113301

4. Balachandar Jayaraman CMN. Husbandry practices and gut health outcomes in weaned piglets: a review. Anim Nutr. (2017) 3:205-11. doi: 10.1016/j.aninu.2017.06.00

5. Han M, Song P, Huang C, Rezaei A, Farrar S, Brown MA, et al. Dietary grape seed proanthocyanidins (GSPs) improve weaned intestinal microbiota and mucosal barrier using a piglet model. Oncotarget. (2016) 7:80313. doi: 10.18632/oncotarget.13450

6. Weiner ML, Ferguson HE, Thorsrud BA, Nelson KG, Blakemore WR, Zeigler $\mathrm{B}$, et al. An infant formula toxicity and toxicokinetic feeding study on carrageenan in preweaning piglets with special attention to the immune system and gastrointestinal tract. Food Chem Toxicol. (2015) 77:120-30. doi: 10.1016/j.fct.2014.12.022

7. Gong J, Yin F, Hou Y, Yin Y. Review: Chinese herbs as alternatives to antibioticsin feed for swine and poultry production: Potential and challenges in application. Can J Anim Sci. (2014) 94:223-41. doi: 10.4141/CJAS2013-144

8. Barba-Vidal E, Martín-Orúe SM, Castillejos L. Practical aspects of the use of probiotics in pig production: a review. Livest Sci. (2019) 223:84-96. doi: 10.1016/j.livsci.2019.02.017

9. Ko SJ, Kim MK, Bang JK, Seo CH, Luchian T, Park Y. Macropis fulvipes venom component macropin exerts its antibacterial and anti-biofilm properties by damaging the plasma membranes of drug resistant bacteria. Sci Rep. (2017) 7:16580. doi: 10.1038/s41598-017-16784-6

10. Wang Y, Wu Y, Wang B, Cao X, Fu A, Li Y, et al. Effects of probiotic Bacillus as a substitute for antibiotics on antioxidant capacity and intestinal autophagy of piglets. AMB Express. (2017) 7:52. doi: 10.1186/s13568-017-0353-x

11. Sonia TA, Ji H, Hong-Seok M, Chul-Ju Y. Evaluation of Lactobacillus and Bacillus-based probiotics as alternatives to antibiotics in enteric microbial challenged weaned piglets. Afr J Microbiol Res. (2014) 8:96-104. doi: 10.5897/AJMR2013.6355

12. Leser TD, Knarreborg A, Worm J. Germination and outgrowth of Bacillus subtilis and Bacillus licheniformis spores in the gastrointestinal tract of pigs. J Appl Microbiol. (2008) 104:1025-33. doi: 10.1111/j.1365-2672.2007.03633.x

13. Poulsen AR, Jonge N, Nielsen JL, Hojberg O, Lauridsen C, Cutting SM, et al. Impact of Bacillus spp. spores and gentamicin on the gastrointestinal microbiota of suckling and newly weaned piglets PLOS ONE. (2018) 13:e207382. doi: 10.1371/journal.pone.0207382

14. Chi C-H, Cho S-J. Improvement of bioactivity of soybean meal by solid-state fermentation with Bacillus amyloliquefaciens versus Lactobacillus spp. and Saccharomyces cerevisiae. Food Sci Technol. (2016) 68:619-25. doi: 10.1016/j.lwt.2015.12.002 of Guangdong Province, China (Grant No. 2017GCZX006), Guangdong Science and Technology Plan Project (Grant No. 2015A020209195), the National Natural Science Foundation of China (Grant No. 31902228), and the Scientific research start-up fund for high-level talents of Foshan University (Grant No. Gg07184).

\section{SUPPLEMENTARY MATERIAL}

The Supplementary Material for this article can be found online at: https://www.frontiersin.org/articles/10.3389/fvets. 2020.584243/full\#supplementary-material

15. Dang Ngoc Quang THYA. Inedible mushrooms: a good source of biologically active substances. Chem Rec. (2006) 6:79-99. doi: 10.1002/tcr.20074

16. Ferreira ICFR, Vaz JA, Vasconcelos MH, Martins A. Compounds from wild mushrooms with antitumor potential. Anticancer Agents Med Chem. (2010) 10:424-36. doi: 10.2174/1871520611009050424

17. Wasser SP. Medicinal mushroom science: history, current status, future trends, and unsolved problems. Int J Med Mushrooms. (2010) 12:1-16. doi: 10.1615/IntJMedMushr.v12.i1.10

18. Huang $\mathrm{X}$, Nie S. The structure of mushroom polysaccharides and their beneficial role in health. Food Funct. (2015) 6:3205-17. doi: 10.1039/C5FO00678C

19. Wong JH, Ng TB, Cheung RC, Ye XJ, Wang HX, Lam SK, et al. Proteins with antifungal properties and other medicinal applications from plants and mushrooms. Appl Microbiol Biotechnol. (2010) 87:1221-35. doi: 10.1007/s00253-010-2690-4

20. $\mathrm{Xu} \mathrm{X}$, Yan $\mathrm{H}$, Chen J, Zhang $\mathrm{X}$. Bioactive proteins from mushrooms. Biotechnol Adv. (2011) 29:667-74. doi: 10.1016/j.biotechadv.2011.05.003

21. Jung B, Lee J, Lee B. Immunoprophylactic effects of shiitake mushroom (Lentinula edodes) against Bordetella bronchiseptica in mice. J Microbiol. (2012) 50:1003-8. doi: 10.1007/s12275-012-2365-1

22. Mahfuz S, Song H, Miao Y, Liu Z. Dietary inclusion of mushroom (Flammulina velutipes) stem waste on growth performance and immune responses in growing layer hens. J Sci Food Agr. (2019) 99:703-10. doi: $10.1002 /$ jsfa.9236

23. Wei-Lian Hu JLJY. Effect of tea saponin on rumen fermentation in vitro. Anim Feed Sci Tech. (2005) 120:333-9. doi: 10.1016/j.anifeedsci.2005.02.029

24. Mao S, Zhang M, Liu J, Zhu W. Characterising the bacterial microbiota across the gastrointestinal tracts of dairy cattle: membership and potential function. Sci Rep. (2015) 5:16116. doi: 10.1038/srep16116

25. Campbell BJ, Polson SW, Hanson TE, Mack MC, Schuur EA. The effect of nutrient deposition on bacterial communities in Arctic tundra soil. Environ Microbiol. (2010) 12:1842-54. doi: 10.1111/j.1462-2920.2010.02189.x

26. Gao K, Pi Y, Peng Y, Mu CL, Zhu WY. Time-course responses of ileal and fecal microbiota and metabolite profiles to antibiotics in cannulated pigs. Appl Microbiol Biotechnol. (2018) 102:2289-99. doi: 10.1007/s00253-018-8774-2

27. Edgar RC. Search and clustering orders of magnitude faster than BLAST. Bioinformatics. (2010) 26:2460-1. doi: 10.1093/bioinformatics/btq461

28. Schloss PD, Westcott SL, Ryabin T, Hall JR, Hartmann M, Hollister $\mathrm{EB}$, et al. Introducing mothur: open-source, platform-independent, community-supported software for describing and comparing microbial communities. Environ Microbiol. (2010) 12:1842-54. doi: 10.1128/AEM. 01541-09

29. Dai BWGW, Liu YSYJ, Wu FHZ. Glutamine and intestinal barrier function. Amino Acids. (2015) 47:2143-54. doi: 10.1007/s00726-014-1773-4

30. Wijtten PJ, van der Meulen J, Verstegen MW. Intestinal barrier function and absorption in pigs after weaning: a review. Br J Nutr. (2011) 105:967-81. doi: 10.1017/S0007114510005660

31. Hu S, Wang Y, Wen X, Wang L, Jiang Z, Zheng C. Effects of low-molecularweight chitosan on the growth performance, intestinal morphology, barrier function, cytokine expression and antioxidant system of weaned piglets. $B M C$ Vet Res. (2018) 14:215. doi: 10.1186/s12917-018-1543-8 
32. Ali Moayedi LMMC, Maryam Hashemi FT. Peptidomic analysis of antioxidant and ACE-inhibitory peptides obtained from tomato waste proteins fermented using Bacillus subtilis. Food Chem. (2018) 18:30041-4. doi: 10.1016/j.foodchem.2018.01.033

33. Chakrabarti S, Guha S, Majumder K. Food-derived bioactive peptides in human health: challenges and opportunities. Nutrients. (2018) 10:1738. doi: $10.3390 /$ nu10111738

34. Jin $\mathrm{H}, \mathrm{Xu} \mathrm{H}, \mathrm{Li} \mathrm{Y}$, Zhang Q, Xie H. Preparation and evaluation of peptides with potential antioxidant activity by microwave assisted enzymatic hydrolysis of collagen from sea cucumber Acaudina Molpadioides obtained from Zhejiang Province in China. Mar Drugs. (2019) 17:169. doi: 10.3390/md17030169

35. Zohreh Karami SHP. Antioxidant, anticancer and ACE-inhibitory activities of bioactive peptides from wheat germ protein hydrolysates. Food Biosci. (2019) 32:100450. doi: 10.1016/j.fbio.2019.100450

36. Kim YI, Lee YH, Kim KH, Oh YK, Moon YH, Kwak WS. Effects of supplementing microbially-fermented spent mushroom substrates on growth performance and carcass characteristics of Hanwoo steers (a field study). Asian Austral J Anim. (2012) 25:1575-81. doi: 10.5713/ajas.2012.12251

37. Hu Y, Dun Y, Li S, Zhao S, Peng N, Liang Y. Effects of Bacillus subtilis KN-42 on growth performance, diarrhea and faecal bacterial flora of weaned piglets. Asian Austral J Anim. (2014) 27:1131-40. doi: 10.5713/ajas.2013.13737

38. Zunxi HZC. Effects of Bacillus coagulans and Bacillus subtilis on the growth performance in weaned piglets. Feed Industry (2017).

39. Ding X, Li H, Wen Z, Hou Y, Wang G, Fan J, et al. Effects of fermented tea residue on fattening performance, meat quality, digestive performance, serum antioxidant capacity, and intestinal morphology in fatteners. Animals. (2020) 10:185. doi: 10.3390/ani10020185

40. Zhou H, Wang C, Ye J, Chen H, Tao R. Effects of dietary supplementation of fermented Ginkgo biloba L. residues on growth performance, nutrient digestibility, serum biochemical parameters and immune function in weaned piglets. Anim Sci J. (2015) 86:790-9. doi: 10.1111/asj.12361

41. Machado-Neto R, Graves CN, Curtis SE. Immunoglobulins in piglets from sows heat-stressed prepartum. J Anim Sci. (1987) 65:445. doi: $10.2527 /$ jas1987.652445x

42. Xu X, Hua H, Wang L, He P, Zhang L, Qin Q, et al. Holly polyphenols alleviate intestinal inflammation and alter microbiota composition in lipopolysaccharide-challenged pigs. Br J Nutr. (2020) 8:881-91. doi: $10.1017 /$ S0007114520000082

43. Jing Wang HJ. Tight junction proteins in the weaned piglet intestine: roles and regulation. Curr Protein Pept Sci. (2019) 20:652-60. doi: 10.2174/1389203720666190125095122

44. Takiishi T, Fenero C, Camara, N. Intestinal barrier and gut microbiota: shaping our immune responses throughout life. Tissue Barriers. (2017) 5:e1373208. doi: 10.1080/21688370.2017.1373208

45. Konstantinov SR, Awati AA, Williams BA, Miller BG, Jones P, Stokes CR, et al. Post-natal development of the porcine microbiota composition and activities. Environ Microbiol. (2006) 8:1191-9. doi: 10.1111/j.1462-2920.2006.01009.x

46. Miller LL, Bly CG, Watson ML, Bale WF. The dominant role of the liver in plasma protein synthesis: direct study of the isolated perfused rat liver with the aid of lysin- - -C14. J Exp Med. (1951) 94:431-53. doi: 10.1084/jem.94.5.431

47. Tian W, Li J, Hu S, Peng X, Li G, Liu X, et al. Proteomic identification of alpha2-HS-glycoprotein as a plasma biomarker of hypopharyngeal squamous cell carcinoma. Int J Clin Exp Patho. (2015) 8:9021-31.

48. Bae Y, Bae Y, Choi M, Choi M, Kim M, Kim M. Manganese supplementation reduces the blood cholesterol levels in Ca-deficient ovariectomized rats. Biol Trace Elem Res. (2011) 141:224-31. doi: 10.1007/s12011-010-8714-1

49. Kristal-Boneh E, Harari G, Green MS. Circannual variations in blood cholesterol levels. Chronobiol Int. (1993) 10:37. doi: 10.3109/07420529309064480

50. Rene L, Van Winsen BAPU, David Keuzenkamp JHMV. Effect of fermented feed on the microbial population of the gastrointestinal tracts of pigs. Appl Environ Microb. (2001) 67:3071-6. doi: 10.1128/AEM.67.7.3071-3076.2001

51. Allison MJ. Production of branched-chain volatile fatty acids by certain anaerobic bacteria. Appl Environ Microbiol. (1978) 5:872. doi: 10.1128/AEM.35.5.872-877.1978

52. Schultz LAML. Metabolism of leucine and valine within the rumen. J Dairy Sci. (1964) 47:1080-5. doi: 10.3168/jds.S0022-0302(64)88849-4

53. Ratajczak W, Ryl A, Mizerski A, Walczakiewicz K, Sipak O, Laszczynska M. Immunomodulatory potential of gut microbiome-derived short-chain fatty acids (SCFAs). Acta Biochim Pol. (2019) 66:1-12. doi: 10.18388/abp.2018_2648

54. Reichardt N, Duncan SH, Young P, Belenguer A, McWilliam LC, Scott KP, et al. Phylogenetic distribution of three pathways for propionate production within the human gut microbiota. ISME J. (2014) 8:1323-35. doi: 10.1038/ismej.2014.14

55. Sommer F, Bäckhed F. The gut microbiota - masters of host development and physiology. Nat Rev Microbiol. (2013) 11:227-38. doi: 10.1038/nrmicro2974

56. Lucy Brooks AVAT. Fermentable carbohydrate stimulates FFAR2-dependent colonic PYY cell expansion to increase satiety. Mol Metab. (2017) 6:48-60. doi: 10.1016/j.molmet.2016.10.011

57. Zhu JJ, Gao MX, Song XJ, Zhao L, Li YW, Hao ZH. Changes in bacterial diversity and composition in the faeces and colon of weaned piglets after feeding fermented soybean meal. J Med Microbiol. (2018) 67:1181-90. doi: $10.1099 /$ jmm.0.000766

58. Delzenne NM, Neyrinck AM, Cani PD. Modulation of the gut microbiota by nutrients with prebiotic properties: consequences for host health in the context of obesity and metabolic syndrome. Microb Cell Fact. (2011) 10:S10. doi: 10.1186/1475-2859-10-S1-S10

59. Heo JM, Opapeju FO, Pluske JR, Kim JC, Hampson DJ, Nyachoti CM. Gastrointestinal health and function in weaned pigs: a review of feeding strategies to control post-weaning diarrhoea without using in-feed antimicrobial compounds. J Anim Physiol Anim Nutr. (2013) 97:207-37. doi: 10.1111/j.1439-0396.2012.01284.x

60. Zhengjun Xie LHYL, Han X. Changes of gut microbiota structure and morphology in weaned piglets treated with fresh fermented soybean meal. World J Microbiol Biotechnol. (2017) 33:213. doi: 10.1007/s11274-017-2374-7

61. Joel R, Wilmore BTG, Daniela Gomez Atria AMM, Daniel P, Beiting DA. Commensal microbes induce serum IgA responses that protect against polymicrobial sepsis. Cell Host Microbe. (2018) 23:302-11. doi: 10.1016/j.chom.2018.01.005

62. Peter Van Baarlen JMWA. Regulation of intestinal homeostasis and immunity with probiotic lactobacilli. Trends Immunol. (2013) 34:208-15. doi: 10.1016/j.it.2013.01.005

63. Ding S, Wang Y, Yan W, Li A, Jiang H, Fang J. Effects of Lactobacillus plantarum 15-1 and fructooligosaccharides on the response of broilers to pathogenic Escherichia coli O78 challenge. PLoS ONE. (2019) 14:e212079. doi: 10.1371/journal.pone.0222877

64. Marta Hugas MGMT. Functionalty of enterococci in meat products. Int J Food Microbiol. (2003) 88:223-33. doi: 10.1016/S0168-1605(03)00184-3

65. Zheng $\mathrm{H}$, Liang $\mathrm{H}$, Wang $\mathrm{Y}$, Miao $\mathrm{M}$, Shi $\mathrm{T}$, Yang $\mathrm{F}$, et al. Altered gut microbiota composition associated with eczema in infants. PLoS ONE. (2016) 11:e166026. doi: 10.1371/journal.pone.0166026

66. Duan Y, Wang Y, Liu Q, Dong H, Li H, Xiong D, et al. Changes in the intestine microbial, digestion and immunity of Litopenaeus vannamei in response to dietary resistant starch. Sci Rep. (2019) 9:6464. doi: 10.1038/s41598-019-42939-8

67. Hwang N, Eom T, Gupta S, Jeong S, Jeong D, Kim Y, et al. Genes and gut bacteria involved in luminal butyrate reduction caused by diet and loperamide. Genes-Basel. (2017) 8:350. doi: 10.3390/genes8120350

68. Li H, Li H, Xie P, Li Z, Yin Y, Blachier F, et al. Dietary supplementation with fermented Mao-tai lees beneficially affects gut microbiota structure and function in pigs. AMB Express. (2019) 9:1-14. doi: 10.1186/s13568-0190747-z

Conflict of Interest: MT and DC were employed by Guangdong Yihao Foodstuff Co., Ltd.

The remaining authors declare that the research was conducted in the absence of any commercial or financial relationships that could be construed as a potential conflict of interest.

Copyright (C) 2020 Qi, Peng, Tang, Chen and Zhang. This is an open-access article distributed under the terms of the Creative Commons Attribution License (CC BY). The use, distribution or reproduction in other forums is permitted, provided the original author(s) and the copyright owner(s) are credited and that the original publication in this journal is cited, in accordance with accepted academic practice. No use, distribution or reproduction is permitted which does not comply with these terms. 